\section{THU0645 VIRTUAL VISITS IS THE FUTURE COMING? TELEREUMATOLOGY. PILOT PROJECT: REVIR PROGRAM, RHEUMATOLOGY SERVICE. BARCELONA, SPAIN}

Fabiola Ojeda ${ }^{1,1}$, Manel Ciria ${ }^{1}$, Carolina Perez-Garcia ${ }^{1}$, Eric Sitjas ${ }^{2}$

Elena Martinez ${ }^{3}$, Daniel Martinez-Laguna ${ }^{4}$, Montserrat Pimienta ${ }^{5}$, Jordi Monfort ${ }^{1}$. ${ }^{1}$ Hospital del Mar, Rheumatology, Barcelona, Spain; ${ }^{2}$ Hospital del Mar, Direction, Barcelona, Spain; ${ }^{3}$ Institut Català de la Salut, CAP Vila Olímpica, Barcelona, Spain; ${ }^{4}$ Institut Català de la Salut, CAP Sant Martí, Barcelona, Spain; ${ }^{5}$ Institut Català de la Salut, CAP Ramón Turró, Barcelona, Spain

Background: The prevalence of rheumatic diseases in the Spanish population is estimated at $22.6 \%$ according to the EPISER 2000 study. A new epidemiological study is currently underway, EPISER 2016 and its preliminary results point towards a higher prevalence. Within the national health system, primary care is the first level of access to the health system and is provided at primary care centers (CAP). The rheumatology at primary care centers at Spain has been a pioneer in the application from the team at Parc de Salut Mar (Hospital del Mar), with the physical presence of rheumatologists in the 14 centers belonging to the CAP network of the SAP Litoral. The high prevalence of the medical pathology of the musculoskeletal syste and the aging of the population, can condition an increase in visit requests in rheumatology, and with it, the increase in the waiting lists of patients.

Objectives: The main objective of this study is to know the resolutive possibility of virtualization, measured in the number of visits resolved telematically, as well as its impact on the resolution capacity of the primary care physician and the reduction of the waiting list of first face-to-face visits.

Methods: Prospective experimental study, started on December 1, 2017 and ended on May 31, 2018. Four primary care centers were selected according to population and waiting list: Sant Martí Nord, Sant Martí Sud, Ramón Turró and Villa Olímpica. The REVIR program proposes the creation of a circuit for the assessment of referrals to rheumatology from primary care physicians (MAP).

Results: 726 first visit requests were received during the REVIR program. The most common categorized pathology was mechanical pathology, representing about $70 \%$ of the first visits requested. Metabolic bone disease ranked second with $16 \%$, and inflammatory pathology ranked third (SLE, RA, SA, SPA, PsA). Chronic musculoskeletal pain ranked fourth (including fibromyalgia) and lastly soft tissue pathology. The number of first visit requests was multiplied by two in all the participating primary care centers of the project. Despite this increase, the telematic resolution of the visits created was stable, with a value greater than $40 \%$.

Conclusion: The implementation of a system of assessment of the first visits in rheumatology requested from Primary Care is effective in decreasing the waiting list to make face-to-face visits, as well as to detect early serious pathology that requires hospital control. It has been achieved, therefore, that the patient is treated at the level of attention that corresponds to him. Guaranteeing the adequate use of hospital resources and reducing the waiting list for a first in-person visit in rheumatology in primary care is one of the most important goals fulfilled, given that it is directly related to maintaining the accessibility and equity of the public health system.

\section{REFERENCES:}

[1] Kataria, S., \& Ravindran, V. (2018). Digital health: a new dimension in rheumatology patient care. Rheumatology International. https://doi.org/ 10.1007/s00296-018-4037-

Tabla 1: Resolution of the first virtual visits to 6 months of REVIR project

\begin{tabular}{lcccc}
\hline CAP & Total & First CAP & First Hospital & Virtual resolution \\
\hline Ramón Turró & $193(26,4 \%)$ & $94(49 \%)$ & $22(11,3 \%)$ & $77(40 \%)$ \\
Villa Olímpica & $96(13,2 \%)$ & $36(37,5 \%)$ & $13(13,5 \%)$ & $47(49 \%)$ \\
Sant Martí (1 y 2) & $437(60,2)$ & $216(49,5 \%)$ & $53(12,1 \%)$ & $168(38,4 \%)$ \\
Total & $726(100 \%)$ & $346(47,6 \%)$ & $88(12,1 \%)$ & $292(40,2 \%)$ \\
\hline
\end{tabular}

Disclosure of Interests: Fabiola Ojeda: None declared, Manel Ciria: None declared, Carolina Perez-Garcia: None declared, Eric Sitjas: None declared, Elena Martinez: None declared, Daniel Martinez-Laguna Speakers bureau: Eli Lilly, Amgen, Ferrer, Rubió and Novartis., Montserrat Pimienta: None declared, Jordi Monfort: None declared DOI: 10.1136/annrheumdis-2019-eular.4250

\section{THU0646 HIGH LEVELS OF DAMAGE IN INFLAMMATORY RHEUMATIC DISEASES: A CLUE TO LOW RATES OF REMISSION AND LOW DISEASE ACTIVITY}

Isabel Castrejon, Sarah Everakes, Joel Block, Sonali Khandelwal, Ailda Nika, Padmanabhan Raghu, Theodore Pincus. Rush University Medical Center, Rheumatology, Chicago, United States of America

Background: Despite introduction of powerful biologic medications over the last 2 decades, rates of remission and low disease activity rates in RA remain less than $50 \%$. One possible basis is that measures and indices such as disease activity score 28 (DAS28) and clinical disease activity index (CDAl), while sensitive primarily to disease activity in clinical trial patients selected for high inflammatory activity, may also reflect clinically important joint damage and patient distress in unselected patients in routine care. Similar considerations may pertain to systemic lupus erythematosus disease activity index (SLEDAl), Bath ankylosing spondylitis disease activity index (BASDAI), and other measures and indices initially designed to assess disease activity. Levels of organ damage and patient distress, as well as inflammation, may be quantitated according to 3 physician (0-10) visual analog scales (VAS), in addition to physician global assessment VAS (DOCGL), scored in fewer than 10 seconds in routine care.

Objectives: To test a hypothesis that damage and distress may be prominent in patients with inflammatory conditions, according to mean VAS for inflammation or reversible findings (DOCINF), damage or irreversible findings (DOCDAM), and distress (DOCSTR), e.g., fibromyalgia.

Methods: All patients at one site complete a multidimensional health assessment questionnaire (MDHAQ), which includes patient global VAS (PATGL), at each visit in routine care. Physicians complete four 0-10 (none-highest) VAS for DOCGL, DOCINF, DOCDAM, and DOCSTR, and a query to estimate the proportion of clinical decisions (total=100\%) attributed to each of the 3 findings. Patients were classified into various diagnostic groups, in which scores were analyzed according to mean and standard deviation.

Results: Analyses included 563 patients (Table). Mean levels of DOCGL ranged from 3.2 to 5.2, and PATGL from 3.6 to 6.5 , which might be interpreted to indicate high disease activity. Highest mean DOCINF scores were seen in patients with RA, SLE, vasculitis, polymyalgia rheumatica (PMR), spondyloarthropathy (SpA), and gout (2.2-2.8), while highest mean DOCDAM was seen in OA (4.9) and DOCSTR in FM (6.2) (Table). How ever, in RA, mean DOCDAM was 3.7 vs 2.4 for DOCINF. DOCDAM also was almost as high or higher than DOCINF in SLE, SpA, vasculitis, and gout. Mean estimates of distress were also $\geq 1.5$ in patients with all inflammatory diagnoses.

\begin{tabular}{|c|c|c|c|c|c|c|}
\hline \multirow[t]{2}{*}{$\begin{array}{l}\text { Diagnosis (per ICD } \\
\text { code) }\end{array}$} & \multirow[t]{2}{*}{$\begin{array}{l}\mathrm{N} \\
(\%)\end{array}$} & \multicolumn{2}{|c|}{$\begin{array}{c}\text { Global Estimates } \\
(0-10)\end{array}$} & \multicolumn{3}{|c|}{ Physician subscales $(0-10)$} \\
\hline & & $\overline{\text { PATGL }}$ & DOCGL & DOCINF & DOCDAM & DOCSTR \\
\hline $\mathrm{RA}$ & 64 & $\begin{array}{l}4.9 \\
(2.9)\end{array}$ & $4.5(2.4)$ & $2.4(2.2)$ & $3.7(2.8)$ & $1.9(2.7)$ \\
\hline SLE & 47 & $\begin{array}{l}4.1 \\
(3.1)\end{array}$ & $3.7(2.8)$ & $2.2(2.4)$ & $1.5(1.7)$ & $1.8(2.5)$ \\
\hline SpA and psoriatic arthritis & 34 & $\begin{array}{l}4.1 \\
(2.9)\end{array}$ & $3.9(2.4)$ & $2.4(2.5)$ & $2.7(2.3)$ & $1.9(2.8)$ \\
\hline Vasculitis and PMR & 23 & $\begin{array}{l}3.6 \\
(2.6)\end{array}$ & $3.4(3.0)$ & $2.6(1.8)$ & $2.3(2.2)$ & $1.7(2.6)$ \\
\hline Gout & 21 & $\begin{array}{l}4.4 \\
(2.9)\end{array}$ & $4.2(2.7)$ & $2.8(2.5)$ & $3.2(2.8)$ & $1.5(1.9)$ \\
\hline Osteoarthritis & 135 & $\begin{array}{l}5.8 \\
(2.9)\end{array}$ & $4.9(2.2)$ & $1.2(1.9)$ & $4.9(2.5)$ & $2.2(2.7)$ \\
\hline Fibromyalgia & 84 & $\begin{array}{l}6.5 \\
(2.6)\end{array}$ & $5.2(2.2)$ & $0.9(1.2)$ & $1.7(2.0)$ & $6.2(2.6)$ \\
\hline Other diagnosis & 155 & $\begin{array}{l}4.0 \\
(3.0)\end{array}$ & $3.2(2.2)$ & $1.6(2.0)$ & $2.4(2.3)$ & $1.6(2.1)$ \\
\hline TOTAL & 563 & $\begin{array}{c}4.8 \\
(3.0)\end{array}$ & $3.9(2.4)$ & $1.6(2.0)$ & $2.9(2.5)$ & $2.4(2.9)$ \\
\hline
\end{tabular}

Conclusion: Rheumatologists estimated high levels of damage in patients with RA and other inflammatory rheumatic diseases, similar or higher than inflammation, as well as recognizable distress which may elevate measures such as tender joint count and PATGL. These findings may explain in part low rates of remission and low disease activity noted in RA and other inflammatory diseases, as index scores used to document improvement are not affected by anti-inflammatory therapy. Most rheumatology clinical quantitative measurement is directed to inflammatory activity. However, an estimate of damage and distress may clarify why many patients may appear to have suboptimal control of inflammatory activity despite aggressive treatment, including treat to target in RA.

Disclosure of Interests: None declared

DOI: 10.1136/annrheumdis-2019-eular.3331 